Original Article

\section{Long-Term Outcomes after Off-Pump Coronary Artery Bypass Grafting in Left Ventricular Dysfunction}

Toshihiro Fukui, MD, Minoru Tabata, MD, MPH, and Shuichiro Takanashi, MD

\begin{abstract}
Purpose: We assessed the long-term clinical, angiographic, and echocardiographic outcomes of patients with left ventricular dysfunction (ejection fraction $\leq 40 \%$ ) who underwent isolated off-pump coronary artery bypass grafting.

Methods: One hundred sixty one patients were included. Mean age was 67.2 \pm 11.4 years, and 20 patients $(12.4 \%)$ were female. Eighty-eight patients $(54.7 \%)$ were New York Heart Association functional class 3 or 4. Early postoperative and follow-up angiography and echocardiography findings were analyzed, and mid-term survival rates (mean follow-up $40.7 \pm 25.6$ months) were calculated.

Results: Mean number of distal anastomoses was $4.4 \pm 1.3$. Bilateral internal thoracic artery grafts were used in $84.5 \%$ of patients. Operative mortality was $2.5 \%$. Early patency rate of anastomoses was $\mathbf{9 8 . 3 \%}$. Early postoperative ejection fraction improved from $33.1 \pm 5.6 \%$ preoperatively to $36.9 \pm 9.5 \%(p<0.001)$. Seven-year survival rate was $73.9 \pm 5.3 \%$, and freedom from cardiac events rate was $68.5 \pm 5.2 \%$. One-year patency rate of anastomoses was $85.8 \%$. Follow-up ejection fraction was $39.1 \pm 10.7 \%(p<0.001)$. Conclusions: Early and long-term outcomes of off-pump coronary artery bypass grafting in patients with left ventricular dysfunction were favorable, including early postoperative and follow-up patency rates of anastomoses and echocardiographic recovery of ejection fraction.
\end{abstract}

Keywords: coronary artery bypass grafting, left ventricular dysfunction, off-pump surgery

\section{Introduction}

Coronary artery bypass grafting (CABG) in patients with left ventricular dysfunction (LVD) is challenging. Multiple revascularizations to viable and hibernating myocardium may improve myocardial contractility and cardiac function even though global function is severely

Department of Cardiovascular Surgery, Sakakibara Heart Institute, Fuchu, Tokyo, Japan

Received: October 13, 2012; Accepted: November 20, 2012 Corresponding author: Toshihiro Fukui, MD. Department of Cardiovascular Surgery, Sakakibara Heart Institute, 3-16-1 Asahimachi, Fuchu, Tokyo 183-0003, Japan

Email: tfukui-cvs@umin.ac.jp

(C)2014 The Editorial Committee of Annals of Thoracic and Cardiovascular Surgery. All rights reserved. impaired. ${ }^{1)}$ Recent meta-analysis demonstrated that CABG can be performed with acceptable operative mortality and 5-year actuarial survival rates in patients with LVD. ${ }^{2)}$ Advances in surgical techniques (such as off-pump techniques and arterial grafts), myocardial protection, and postoperative management have contributed to improving outcomes in these high-risk patients. An outcome comparison between on-pump CABG and off-pump CABG did not find a significant difference in operative mortality between the two groups (5.4\% in the on-pump group versus $4.4 \%$ in the off-pump group). ${ }^{2)}$ However, another study including a larger number of patients found that operative mortality was significantly higher in the on-pump group (6.4\%) than the off-pump group (4.2\%), even though the off-pump group had a significantly lower rate $(62.9 \%)$ of complete revascularization than 
the on-pump group (89.9\%). . $^{3)}$ The mid-and long-term surival benefits of off-pump CABG are still unclear.

At our institute, the strategy for isolated CABG has been to obtain complete revascularization using an offpump technique whenever feasible. In this retrospective study, we assessed 1) the early and long-term clinical outcomes, and 2) the early postoperative and follow-up angiographic and echocardiographic data, in patients with LVD who underwent off-pump CABG.

\section{Patients and Methods}

\section{Patient population}

From September 2004 to July 2011, 1278 patients underwent isolated CABG at Sakakibara Heart Institute. Of these, 161 patients with left ventricular ejection fraction (LVEF) $\leq 40 \%$ were enrolled in this study (mean ejection fraction $33.0 \pm 5.7 \%$ ). Patients who underwent concomitant valve surgery, ventricular aneurysmectomy, or aortic surgery were excluded. The remaining patients without a left ventricular aneurysm or severe ischemic mitral regurgitation underwent isolated CABG. Our strategy for surgical intervention was complete revascularization. Angiographic stenosis of $\geq 50 \%$ was considered significant. All patients underwent preoperative transthoracic echocardiography to examine left ventricular function. The baseline characteristics of the 161 patients are shown in Table $\mathbf{1 .}$

The Institutional Review Board of our institution approved this retrospective study and waived the need for written consent. Follow-up involved direct communication with the patient, the patient's family, or the attending physician, or a combination of these.

\section{Operation}

General anesthesia was induced with midazolam $(0.2 \mathrm{mg} / \mathrm{kg})$ and fentanyl $(4 \mathrm{ug} / \mathrm{kg})$. Neuromuscular block was achieved with vecuronium $(0.1 \mathrm{mg} / \mathrm{kg})$. After the intubation of a trachea, the lung was ventilated with $2 \%-2.5 \%$ of sevoflurane with an air-oxygen mixture. Nicorandil and landiolol, a short acting beta-one selective antagonist, were administered throughout the operation. Anticoagulation was achieved with heparin at $300 \mathrm{U} / \mathrm{kg}$ after all grafts were harvested for coronary revascularization. Phenylephrine was continuously administered during distal coronary anastomosis to maintain the mean blood pressure above $60 \mathrm{mmHg}$ without accelerating the heart rate. Beta agonists were administered after the proximal anastomosis if necessary.
Table 1 Preoperative, operative and postoperative data

\begin{tabular}{|c|c|}
\hline Variable & $\begin{array}{c}\text { Mean } \pm \text { SD or number } \\
\text { of patients }(\%)\end{array}$ \\
\hline Total number & 161 \\
\hline Age & $67.2 \pm 11.4$ \\
\hline Female gender & $20(12.4 \%)$ \\
\hline Body surface area $\left(\mathrm{m}^{2}\right)$ & $1.7 \pm 0.2$ \\
\hline Non-elective & $35(21.7 \%)$ \\
\hline Heat failure in the past & $94(58.4 \%)$ \\
\hline $\begin{array}{l}\text { New York Heart Association } \\
\text { class III or IV }\end{array}$ & $88(54.7 \%)$ \\
\hline Hypertension & $101(62.7 \%)$ \\
\hline Diabetes mellitus & $90(55.9 \%)$ \\
\hline Hyperlipidemia & $98(60.9 \%)$ \\
\hline Smoking history & $104(64.6 \%)$ \\
\hline Creatinine (mg/dl) & $1.3 \pm 1.3$ \\
\hline $\begin{array}{l}\text { Chronic obstructive pulmonary } \\
\text { disease }\end{array}$ & $9(5.6 \%)$ \\
\hline Peripheral vascular disease & $21(13.0 \%)$ \\
\hline $\begin{array}{l}\text { Preoperative use of intraaortic } \\
\text { balloon pumping }\end{array}$ & $28(17.4 \%)$ \\
\hline Redo & $5(3.1 \%)$ \\
\hline Mean anastomoses & $4.4 \pm 1.3$ \\
\hline $\begin{array}{l}\text { Bilateral internal thoracic } \\
\text { artery use }\end{array}$ & $136(84.5 \%)$ \\
\hline Intensive care unit stay (days) & $4.2 \pm 19.6$ \\
\hline Operative death & $4(2.5 \%)$ \\
\hline Low output syndrome & $12(7.5 \%)$ \\
\hline Stroke & $5(3.1 \%)$ \\
\hline Re-exploration for bleeding & $3(1.9 \%)$ \\
\hline $\begin{array}{l}\text { Renal failure requiring } \\
\text { hemodialysis }\end{array}$ & $6(3.7 \%)$ \\
\hline Respiratory failure & $11(6.8 \%)$ \\
\hline Mediastinitis & $4(2.5 \%)$ \\
\hline
\end{tabular}

The patients were placed in the Trendelenburg position. The right pleura was widely opened to avoid right heart compression and obstruction of venous return. Deep pericardial stay sutures were not used, and a commercially available heart positioner and stabilizer were applied in all cases.

Our operative technique for off-pump CABG has been described previously.4) All arterial grafts were harvested in a skeletonized fashion using an ultrasonic scalpel (Harmonic Scalpel, Ethicon Endosurgery, Cincinnati, Ohio, USA). We bypassed all significantly diseased coronary vessels ( $\geq 50 \%$ diameter reduction) which were $>1 \mathrm{~mm}$ in diameter. We performed long segmental reconstruction when the left anterior descending artery was diffusely diseased, and branches such as the septal and diagonal arteries were affected by severe atheromatous plaque. The detailed indications, techniques, and outcomes of long segmental reconstruction of the left anterior descending artery have been described previously. ${ }^{5}$ ) 
We routinely prescribed low-dose aspirin to all patients postoperatively, continued indefinitely. Patients who underwent saphenous vein grafting also received warfarin for 3 months, with a target international normalized ratio of 2.0.

\section{Angiographic and echocardiographic studies}

Early postoperative and follow-up angiography to assess the patency of anastomoses were performed only in patients who gave informed consent. Early postoperative angiography was performed in 121 patients (75.2\%) during the same hospitalization (10.6 \pm 6.4 days after surgery), and follow-up angiography was performed in 77 patients $(47.8 \%)$ at $13.6 \pm 6.6$ months after surgery.

Two-dimensional imaging of intracardiac structures and estimations of blood flow were performed using an HP Sonos imaging system (Hewlett-Packard Co., Andover, Massachusetts, USA). Ejection fraction was calculated using the modified Simpson 2D volumetric method. Early postoperative echocardiographic examination was performed in 155 patients $(96.3 \%)$ during the same hospitalization (7.0 \pm 1.5 days after surgery), and follow-up echocardiographic examination was performed in 115 patients $(71.4 \%)$ at $21.9 \pm 20.4$ months after surgery in our outpatient clinic.

\section{Definitions}

Non-elective operations included both emergency and urgent cases, according to the definitions in the Society of Thoracic Surgeons database. Operative death was defined as death occurring during the same hospitalization, or after discharge but within 30 days after surgery. Lowoutput syndrome was defined as the postoperative need for intra-aortic balloon pumping, or any dose of adrenaline, or $>5 \mu \mathrm{g} / \mathrm{kg} / \mathrm{min}$ of dopamine or dobutamine. Perioperative myocardial infarction was defined as new $\mathrm{Q}$ waves on electrocardiography or a peak creatine kinase MB level of greater than or equal to five times the upper limit of normal (25 IU/L). Respiratory failure was defined a requirement for prolonged ventilation ( $>48$ hours) or the occurrence of pneumonia. Postoperative stroke was defined as a new neurological deficit that was detected on computed tomography. In patients with preoperative stroke, postoperative stroke was defined as a worsening of the neurological deficit with new radiological findings. Follow-up analysis examined all cardiac events including death, heart failure, and myocardial infarction.

A patent graft anastomosis was defined as an anastomosis without occlusion, significant stenosis ( $\geq 90 \%)$, or a string sign near the anastomosis. A string sign was defined as luminal narrowing of the graft, including stenosis of $\geq 90 \%$. Early postoperative and follow-up patency rates were calculated by dividing the number of patent anastomoses by the total number of anastomoses. If patients with early non-patent anastomoses underwent follow-up angiography, the early non-patent anastomoses were also counted as follow-up nonpatent anastomoses.

\section{Statistical analysis}

Continuous variables are reported as the mean \pm standard deviation. Continuous variables were compared using the Student's t-test, and discrete variables were compared using the $\chi^{2}$ test or Fischer's exact test. Actuarial survival curves were estimated using the Kaplan-Meier method. Multivariate Cox proportional hazards analysis was performed to identify significant predictors of late mortality, using the clinical variables listed in Table 1. A $p$ value of $<0.05$ was considered statistically significant. Statistical analyses were performed using StatView software, version 5.0 (SAS Institute Inc., Cary, North Carolina, USA).

\section{Results}

\section{Early and long-term clinical outcomes}

Table 1 shows intraoperative and postoperative data. The mean number of distal anastomoses per patient was $4.4 \pm 1.3$. At least one internal thoracic artery was used in $100 \%$ of patients, and both the left and right internal thoracic arteries were used in $84.5 \%$ of patients. Intra-aortic balloon pumping was used perioperatively in 28 patients (17.4\%): prophylactically in 26 patients, and to treat low intraoperative cardiac output in 2 patients.

The operative mortality rate was $2.5 \%$ (4 patients). The cause of death was pneumonia in two patients, congestive heart failure in one patient, and mediastinitis in one patient. The mean length of tracheal intubation after surgery was $12.3 \pm 14.7$ hours. The median length of intensive care unit stay after surgery was 1 day (range 1-210 days), and the median length of hospital stay after surgery was 16 days (range 7-337 days).

The mean follow-up period was $40.7 \pm 25.6$ months after surgery. At 7 years postoperatively, the rate of freedom from all death was $73.9 \pm 5.3 \%$ (Fig. 1), and rate of freedom from cardiac events was $68.5 \pm 5.2 \%$ (Fig. 2). Among survivors, the mean New York Heart 


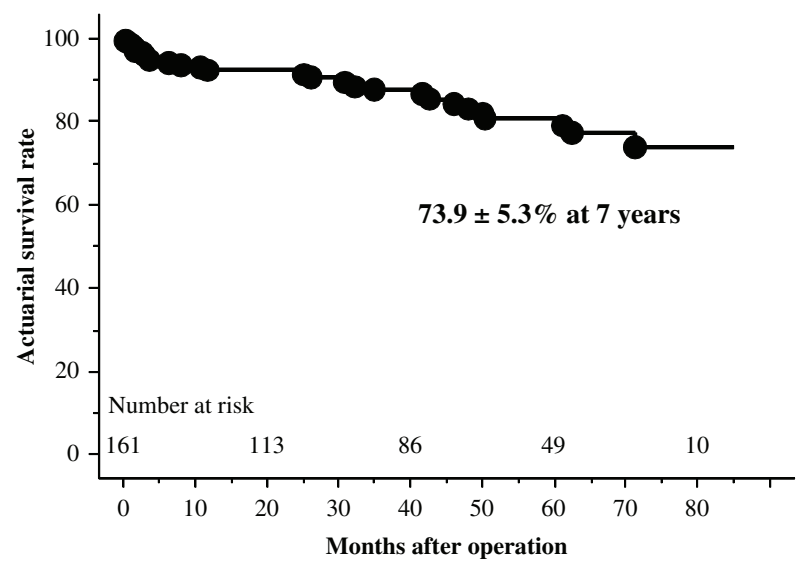

Fig. 1 Freedom from death in patients with left ventricular dysfunction who underwent isolated off-pump coronary artery bypass grafting.

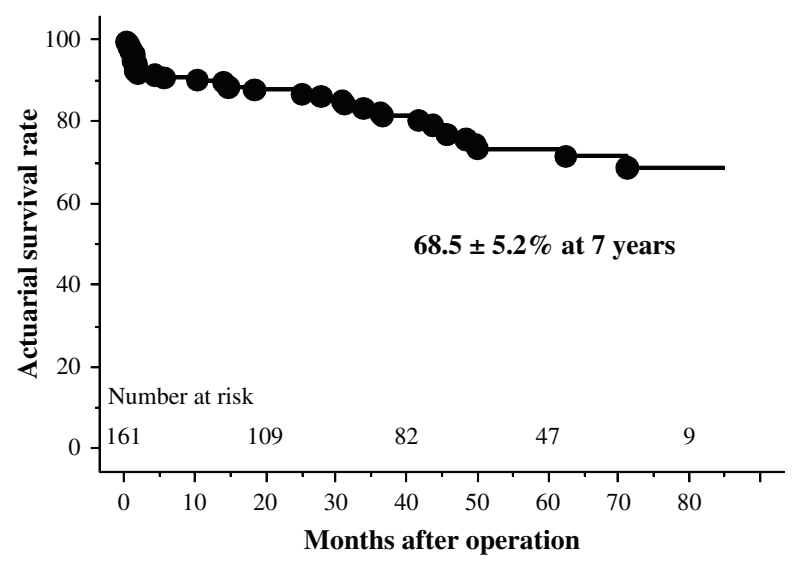

Fig. 2 Freedom from cardiac events (all death, heart failure, and myocardial infarction) in patients with left ventricular dysfunction who underwent isolated off-pump coronary artery bypass grafting.

Table 2 Angiographic patency rates of anastomoses

\begin{tabular}{llllll}
\hline & \multicolumn{1}{c}{ ITA } & \multicolumn{1}{c}{ RA } & \multicolumn{1}{c}{ GEA } & \multicolumn{1}{c}{ SVG } & Total \\
\hline Early & $251 / 253(99.2 \%)$ & $82 / 82(100 \%)$ & $15 / 15(100 \%)$ & $173 / 180(96.1 \%)$ & $521 / 530(98.3 \%)$ \\
Follow-up & $140 / 148(94.6 \%)$ & $46 / 58(79.3 \%)$ & $4 / 6(66.7 \%)$ & $89 / 113(78.8 \%)$ & $279 / 325(85.8 \%)$ \\
\hline
\end{tabular}

ITA: internal thoracic artery; RA: radial artery; GEA: gastroepiploic artery; SVG: saphenous vein graft

Association functional class improved significantly from $2.6 \pm 0.9$ preoperatively to $1.3 \pm 0.6$ at follow-up $(p<0.01)$.

Multivariate analysis using the Cox proportional hazards model identified only preoperative high creatinine level as a predictor of long-term mortality (hazard ratio $1.28 ; 95 \%$ confidence interval $1.07-1.53 ; p<0.01)$.

\section{Early postoperative and follow-up angiographic outcomes}

The patency rates of anastomoses are shown in Table 2. At early postoperative angiography, the patency rates were close to $100 \%$ for all grafts. At follow-up angiography, the patency rates of anastomoses of the radial artery, gastroepiploic artery, and saphenous vein grafts were all $<80 \%$, and of the internal thoracic artery grafts was $>90 \%$. The patency rates of anastomoses were better for arterial grafts (internal thoracic artery, gastroepiploic artery, and radial artery) than saphenous vein grafts $(89.6 \%$ vs. $78.8 \% ; p=0.01)$.

\section{Early postoperative and follow-up echocardiographic outcomes}

Preoperative and postoperative echocardiographic data are shown in Table 3. LVEF and all parameters of left ventricular diameter and volume were significantly improved at early postoperative echocardiography. These improvements continued at follow-up echocardiography.

\section{Discussion}

The present study shows that isolated off-pump CABG in patients with LVD can achieve acceptable early and long-term clinical outcomes. Furthermore, early postoperative and follow-up angiographic patency rates of the internal thoracic artery were favorable, and echocardiographic improvements of cardiac function were achieved.

Preoperative LVEF is a powerful predictor of operative mortality. Early mortality rates are higher in patients with LVD than without LVD. ${ }^{6,7)}$ Recent studies have reported early postoperative mortality rates of $1.7 \%-11 \%$ in patients with LVD. ${ }^{1,6-17)}$ The operative mortality rate in this study $(2.5 \%)$ was similar to that reported in other studies, indicating the safety of the off-pump technique for patients with LVD.

Recently, several studies have reported outcome comparisons between off-pump and on-pump CABG in patients with LVD. Some of these studies found that off-pump CABG had better outcomes than on-pump 
Table 3 Preoperative and postoperative echocardiographic data

\begin{tabular}{lccr}
\hline Number $=156$ & Preoperative & Early Postoperative & $p$ value \\
\hline Ejection fraction $(\%)$ & $33.1 \pm 5.6$ & $36.9 \pm 9.5$ & $<0.01$ \\
LVDd $(\mathrm{mm})$ & $55.2 \pm 6.3$ & $53.2 \pm 6.6$ & $<0.01$ \\
LVDs $(\mathrm{mm})$ & $45.0 \pm 7.7$ & $43.0 \pm 7.8$ & 0.03 \\
EDVI $(\mathrm{ml} / \mathrm{m} 2)$ & $92.8 \pm 24.8$ & $82.7 \pm 23.6$ & $<0.01$ \\
ESVI $(\mathrm{ml} / \mathrm{m} 2)$ & $62.7 \pm 20.0$ & $53.3 \pm 20.8$ & $<0.01$ \\
\hline Number $=118$ & Preoperative & Follow-up & $p$ value \\
\hline Ejection fraction $(\%)$ & $33.1 \pm 5.6$ & $39.1 \pm 10.7$ & $<0.01$ \\
LVDd $(\mathrm{mm})$ & $56.0 \pm 6.2$ & $52.5 \pm 7.3$ & $<0.01$ \\
LVDs $(\mathrm{mm})$ & $45.4 \pm 8.1$ & $42.6 \pm 8.6$ & 0.01 \\
EDVI $(\mathrm{ml} / \mathrm{m} 2)$ & $92.8 \pm 24.6$ & $84.2 \pm 28.3$ & 0.03 \\
ESVI $(\mathrm{ml} / \mathrm{m} 2)$ & $62.5 \pm 20.0$ & $53.4 \pm 25.4$ & $<0.01$ \\
\hline Values are expressed as the mean \pm SD. LVDd: diastolic left ventricular di- \\
ameter; LVDs: systolic left ventricular diameter; EDVI: end-diastolic vol- \\
ume index; ESVI: end-systolic volume index
\end{tabular}

CABG. Masoumi and colleagues ${ }^{18)}$ conducted a study comparing patients undergoing off-pump CABG and on-pump CABG (62 patients in each group). They concluded that in-hospital mortality was significantly lower in the off-pump group than the on-pump group (0\% vs. $6.5 \%, p<0.05)$. Caputti and colleagues ${ }^{19)}$ conducted an observational study and found that in-hospital mortality was significantly lower in patients undergoing offpump CABG than on-pump CABG $(3.8 \%$ vs. $12.5 \%$, $p=0.008$ ). However, other studies did not find that off-pump CABG had better outcomes than on-pump CABG. Attaran and colleagues ${ }^{20)}$ conducted a retrospective study, which included the largest study population reported to date, and found no significant difference in in-hospital mortality rates between the off-pump and on-pump groups $(5.7 \%$ vs. $7.8 \%, p=0.21)$. Jarral and colleagues $^{21)}$ concluded in a review article that there is limited evidence to associate the off-pump CABG technique with improved short-term mortality. However, they speculated that the results may be affected by a lack of experience with off-pump CABG because the data included operations performed prior to the year 2000 . Off-pump CABG may be more technically demanding in patients with LVD.

Complete revascularization is one of the major goals of CABG. Patients who undergo incomplete revascularization have worse outcomes after CABG than those who undergo complete revascularization. ${ }^{22)}$ Several studies have documented that appropriate myocardial revascularization in patients with LVD improves their quality of life, ${ }^{23)}$ left ventricular contractility, ${ }^{13)} \mathrm{LVEF},{ }^{14)}$ and New York Heart Association functional class. ${ }^{24)}$ However, a lower number of anastomoses was reported in patients with LVD who underwent off-pump CABG than those who underwent on-pump CABG. ${ }^{3)}$ In the present study, we performed complete revascularization in all patients, with a mean number of 4.4 distal anastomoses per patient, which was higher than in any other studies. We achieved good early angiographic patency rates in both artery and vein grafts. However, the followup patency rates were not good, except for internal thoracic artery grafts. We believe that bilateral internal thoracic artery grafts should be used frequently even in patients with LVD because they have superior long-term patency rates compared with other grafts.

In the present study, CABG resulted in significant improvements in LVEF and all left ventricular dimensions and volumes. Carr and colleagues ${ }^{13)}$ found ongoing improvement in LVEF during follow-up. They reported that the preoperative mean LVEF of $18 \pm 3 \%$ improved to $36 \pm 14 \%$ at $4-6$ years after surgery, and suggested that this improvement was due to a decrease in left ventricular systolic diameter despite a lack of change in diastolic diameter. In the present study, significant decreases in both diastolic and systolic dimensions and volumes were observed, in association with improved LVEF.

Recent studies have reported 5-year survival rates after CABG in patients with LVD of $56 \%-80 \% .^{1,7-9,11,13,14,25)}$ Attaran and colleagues ${ }^{20)}$ reported no significant differences in long-term survival between off-pump and on-pump CABG, with 5- and 10-year survival rates after off-pump CABG of $75.4 \%$ and $71.8 \%$, respectively. Their survival rates were similar to those found in the present study. Multivariate analysis identified only preoperative creatinine level as a predictor of long-term mortality in the present study. Hillis and colleagues ${ }^{10)}$ 
also identified renal dysfunction as the strongest independent predictor of mortality. It is still unclear whether the off-pump technique improves long-term outcomes in patients with LVD.

\section{Study limitations}

The main limitation of this study is the small number of patients. Postoperative angiographic and echocardiographic data could not be obtained in all patients. Furthermore, this was a retrospective observational study and was not randomized.

\section{Conclusions}

Early and long-term outcomes of off-pump CABG in patients with LVD were favorable. Early postoperative and follow-up patency rates of anastomoses and echocardiographic recovery of LVEF were also favorable.

\section{Disclosure Statement}

There are no conflicts of interest.

\section{References}

1) Lorusso R, La Canna G, Ceconi C, et al. Long-term results of coronary artery bypass grafting procedure in the presence of left ventricular dysfunction and hibernating myocardium. Eur J Cardiothorac Surg 2001; 20: $937-48$.

2) Kunadian V, Zaman A, Qiu W. Revascularization among patients with severe left ventricular dysfunction: a meta-analysis of observational studies. Eur J Heart Fail 2011; 13: 773-84.

3) Jarral OA, Saso S, Athanasiou T. Off-pump coronary artery bypass in patients with left ventricular dysfunction: a meta-analysis. Ann Thorac Surg 2011; 92: 1686-94.

4) Fukui T, Tabata M, Manabe S, et al. Graft selection and one-year patency rates in patients undergoing coronary artery bypass grafting. Ann Thorac Surg 2010; 89: 1901-5.

5) Fukui T, Tabata M, Taguri M, et al. Extensive reconstruction of the left anterior descending coronary artery with an internal thoracic artery graft. Ann Thorac Surg 2011; 91: 445-51.

6) Topkara VK, Cheema FH, Kesavaramanujam S, et al. Coronary artery bypass grafting in patients with low ejection fraction. Circulation 2005; 112: I344-50.

7) Appoo J, Norris C, Merali S, et al. Long-term outcome of isolated coronary artery bypass surgery in patients with severe left ventricular dysfunction. Circulation 2004; 110: III3-7.
8) Mickleborough LL, Carson S, Tamariz M, et al. Results of revascularization in patients with severe left ventricular dysfunction. J Thorac Cardiovasc Surg 2000; 119: 550-7.

9) Shapira OM, Hunter CT, Anter E, et al. Coronary artery bypass grafting in patients with severe left ventricular dysfunction-early and mid-term outcomes. J Card Surg 2006; 21: 225-32.

10) Hillis GS, Zehr KJ, Williams AW, et al. Outcome of patients with low ejection fraction undergoing coronary artery bypass grafting: renal function and mortality after 3.8 years. Circulation 2006; 114: I414-9.

11) Shah PJ, Hare DL, Raman JS, et al. Survival after myocardial revascularization for ischemic cardiomyopathy: a prospective ten-year follow-up study. J Thorac Cardiovasc Surg 2003; 126: 1320-7.

12) Ascione R, Narayan P, Rogers CA, et al. Early and midterm clinical outcome in patients with severe left ventricular dysfunction undergoing coronary artery surgery. Ann Thorac Surg 2003; 76: 793-9.

13) Carr JA, Haithcock BE, Paone G, et al. Long-term outcome after coronary artery bypass grafting in patients with severe left ventricular dysfunction. Ann Thorac Surg 2002; 74: 1531-6.

14) Bouchart F, Tabley A, Litzler PY, et al. Myocardial revascularization in patients with severe ischemic left ventricular dysfunction. Long term follow-up in 141 patients. Eur J Cardiothorac Surg 2001; 20: $1157-62$.

15) Darwazah AK, Abu Sham'a RA, Hussein E, et al. Myocardial revascularization in patients with low ejection fraction $<$ or $=35 \%$ : effect of pump technique on early morbidity and mortality. J Card Surg 2006; 21: 22-7.

16) Nurözler F, Kutlu ST, Küçük G. Coronary by-pass for bad ventricle; adoption of "hybrid-pump" bypass. J Cardiothorac Surg 2006; 1: 44.

17) McCarron EE, Shackcloth MJ, Grayson AD, et al. Left internal mammary artery use in patients with poor left ventricular ejection fraction: a propensity-matched analysis of mid-term survival. Interact Cardiovasc Thorac Surg 2005; 4: 184-8.

18) Masoumi M, Saidi MR, Rostami F, et al. Off-pump coronary artery bypass grafting in left ventricular dysfunction. Asian Cardiovasc Thorac Ann 2008; 16: 16-20.

19) Caputti GM, Palma JH, Gaia DF, et al. Off-pump coronary artery bypass surgery in selected patients is superior to the conventional approach for patients with severely depressed left ventricular function. Clinics (Sao Paulo) 2011; 66: 2049-53.

20) Attaran S, Shaw M, Bond L, et al. Does off-pump coronary artery revascularization improve the longterm survival in patients with ventricular dysfunction? Interact Cardiovasc Thorac Surg 2010; 11: 442-6.

21) Jarral OA, Saso S, Athanasiou T. Does off-pump coronary artery bypass surgery have a beneficial effect on 
mortality in patients with left ventricular dysfunction? Interact Cardiovasc Thorac Surg 2012; 14: 856-64.

22) Kleisli T, Cheng W, Jacobs MJ, et al. In the current era, complete revascularization improves survival after coronary artery bypass surgery. J Thorac Cardiovasc Surg 2005; 129: 1283-91.

23) Elefteriades JA, Morales DL, Gradel C, et al. Results of coronary artery bypass grafting by a single surgeon in patients with left ventricular ejection fractions $<$ or $=30 \%$. Am J Cardiol 1997; 79: 1573-8.
24) Elefteriades JA, Tolis G, Levi E, et al. Coronary artery bypass grafting in severe left ventricular dysfunction: excellent survival with improved ejection fraction and functional state. J Am Coll Cardiol 1993; 22: 1411-7.

25) DeRose JJ, Toumpoulis IK, Balaram SK, et al. Preoperative prediction of long-term survival after coronary artery bypass grafting in patients with low left ventricular ejection fraction. J Thorac Cardiovasc Surg 2005; 129: $314-21$. 